\title{
Avaliação de desempenho de um conjunto motor e ventilador de um evaporador de $\mathrm{NH}_{3}$
}

Performance evaluation of the motor and fan assembly of an $\mathrm{NH}_{3}$ evaporator

\author{
M. M. Rebelato ${ }^{1 *}$; J. F. Rodrigues ${ }^{2}$; F. L. C. Carrir ${ }^{3}$; M. M. Galarça ${ }^{1,2,3}$; \\ I. C. Acunha $\mathrm{Jr}^{1,2,3}$ \\ ${ }^{1}$ Tecnologia em Refrigeração e Climatização, IFRS-Campus Rio Grande, CEP 96201-460, Rio Grande-RS, \\ Brasil. \\ ${ }^{2}$ Engenharia Mecânica, IFRS-Campus Rio Grande, CEP 96201-460, Rio Grande-RS, Brasil. \\ ${ }^{3}$ Programa de Pós-Graduação em Modelagem Computacional - FURG, Rio Grande, CEP 96201-900, Rio Grande- \\ RS, Brasil.
}

*ivoni.acunha@riogrande.ifrs.edu.br

(Recebido em 05 de março de 2018; aceito em 26 de setembro de 2018)

\begin{abstract}
O consumo de energia das plantas frigoríficas, em geral, é o mais significativo nos processos de produção e armazenamento de alimentos refrigerados. Os motores dos ventiladores de evaporadores tem grande contribuição, tanto no consumo energético, quanto no acréscimo da taxa de calor nas câmaras frigoríficas. Técnicas como a utilização de inversores de frequência para acionamento destes motores tendem a atenuar estes impactos referentes ao consumo e calor gerado no interior de câmaras frigoríficas. Assim, este trabalho tem como objetivo avaliar o desempenho de um conjunto motor e ventilador de um evaporador de $\mathrm{NH}_{3} \mathrm{em}$ duas condições de operação sob diferentes rotações, impostas por um inversor de frequência utilizado para acionamento. Os ensaios foram realizados com frequências de $20 \mathrm{a} 60 \mathrm{~Hz}$ com incrementos de $5 \mathrm{~Hz}$. As amostras foram obtidas a partir de medições de velocidade de ar, medições da variação de pressão provocada pelo feixe tubular e pelo aletamento do evaporador e medições do consumo de energia. O melhor desempenho do evaporador ocorre quando o mesmo opera com a vedação em suas frestas. A utilização de inversor de frequência promoveu uma redução significativa, de até $90 \%$ no consumo energético, do motor do ventilador operando na frequência de $20 \mathrm{~Hz}$, em relação à condição nominal de operação de $60 \mathrm{~Hz}$. Esta forma de operação acarretará em economia de energia nas ocasiões em que não houver demanda da capacidade máxima de refrigeração e na redução do calor gerado no interior das câmaras.
\end{abstract}

Palavras-chave: Evaporador de $\mathrm{NH}_{3}$, Ventilador, Velocidade Variável, Potência consumida

The energy consumption of refrigeration plants is, in general, the most significant in the production and storage of refrigerated food. The motors of the evaporator fans have a great contribution, both in energy consumption and in the increase of the heat transfer rate inside of cold rooms. Techniques such as the use of frequency inverters to drive these motors tend to attenuate these impacts regarding the consumption and heat generated inside storage chambers. Aims of this work is evaluate the performance of a motor and fan assembly of an $\mathrm{NH}_{3}$ evaporator under two operating conditions under different rotations, imposed by a frequency inverter drive. The tests were performed with frequencies of 20 to $60 \mathrm{~Hz}$ with increments of 5 Hz. Samples is obtained from measurements of air velocity, measurements of the pressure drop caused by the tubular bundle and by the evaporator smoothing and measurements of the energy consumption. The best performance of the evaporator occurs when it operates with the seal in its cracks. The use of frequency inverters can promote a significant reduction, about $90 \%$ in energy consumption of the fan motor operating at the frequency of $20 \mathrm{~Hz}$, compared to the nominal operating condition of $60 \mathrm{~Hz}$. This form of operation will entail in energy saving in those cases where there is no demand for maximum cooling capacity and in the reduction of the heat generated inside the cold chambers.

Keywords: $\mathrm{NH}_{3}$ Evaporator, Fan, Variable speed, Power consumption 


\section{INTRODUÇÃO}

O consumo de energia das plantas frigoríficas, em geral, é o mais significativo nos processos de produção e armazenamento de alimentos refrigerados. Os motores dos ventiladores de evaporadores tem grande contribuição, tanto no consumo energético, quanto no acréscimo da taxa de calor nas câmaras frigoríficas. Técnicas como a utilização de inversores de frequência para acionamento destes motores tendem a atenuar estes impactos referentes ao consumo e calor gerado.

Qureshi e Tassou (1996) [1] demonstram no seu estudo, que várias técnicas têm sido usadas para controle de capacidade, mas o variador de velocidade foi mostrado ser a tecnologia mais eficaz e flexível em comparação com outras técnicas, como bypass de gás quente, controle de temperatura do evaporador baseado em uma válvula de expansão eletrônica, controle de compressores e carregamento de cilindros.

Como Stoecker e Jabarbo (2002) [2] destacam, o compressor é o componente que mais consome energia do sistema de refrigeração, a ponto de afetar significativamente o custo de operação da instalação. Para isso é indispensável o conhecimento dos regimes de compressão, plano de manutenção, seleção adequada de cada equipamento no momento do projeto, afim de que estejam bem dimensionados para assegurar o bom funcionamento e garantir a melhor eficiência. A partir disso, tendo como base o principio básico do sistema de refrigeração por compressão a vapor para um sistema de refrigeração comercial, Pinnola et al. (2015) [3] pode concluir que o sistema que opera usando um inversor de frequência e um controlador lógico programável $(C L P)$ em relação ao sistema com controle on-off convencional, mostrou economia de consumo de energia de até $31 \%$ em um período de teste de $6 \mathrm{~h}$ e 10 min e que a frequência de ciclo do compressor do sistema no sistema que opera com o controle de frequência é menor do que com o sistema on-off tradicional.

Como os sistemas de resfriamento em minas da África do Sul são identificados como grandes consumidores de eletricidade, Plessis et al. (2013) [4] desenvolveram um estudo de implementação piloto em uma mina, onde é demonstrado que a implementação em grande escala de VSDs (tecnologia de velocidade variável) em bombas e ventiladores de sistemas de arrefecimento de minas é economicamente viável e pode alcançar uma economia anual de energia elétrica total de $144.721 \mathrm{MWh}$, ou 32,2\%. É possível uma economia de custo anual de US \$ 6.938.148 e redução de emissões de $\mathrm{CO}_{2}$ de 132 Mton. A implementação de VSDs em compressores de resfriamento de mina também resultará em grandes economias de energia, mas não é economicamente viável no momento. Os resultados do estudo piloto indicam uma economia de eletricidade de $29,9 \%$.

No trabalho de Zhifang e Lin (2010) [5] para o caso proposto, a redução do consumo de energia, a regulagem da capacidade do sistema e a combinação das cargas do compressor com as necessidades de aquecimento ou resfriamento, são somente obtidas apenas através do controle de velocidade variável em bombas de calor de fonte de água e condicionadores de ar por meio da conversão de frequência. Por outro lado, no estudo de Yu e Chan (2006) [6] é constatado que o uso de ventiladores com velocidade variável no condensador, aliado com o controle da temperatura de condensação e usados em conjunto nos chiller parafuros refrigeradores de ar, permite que operem com mais eficiência, podendo reduzir seu consumo anual de eletricidade normalizado pela área total do piso do edifício de $56,2 \mathrm{kWh} / \mathrm{m}^{2}$ para $44 \mathrm{kWh} / \mathrm{m}^{2}$.

No estudo de Al-Bassam e Alasseri (2013) [7] na temporada de verão de Kuwait, visando saber qual seria o efeito da instalação de inversores de frequência variável em ventiladores de torres de resfriamentos em relação ao sistema de dupla velocidade, foi constatado que o sistema com tecnologia de velocidade variável é uma solução tanto para redução de $12 \%$ no consumo na água, quanto na economia de energia, onde a potência consumida combinadas dos chillers e ventiladores das torres de resfriamentos foram reduzidos em $5,8 \%$.

Já no estudo de Soyguder (2011) [8], a fim de minimizar o consumo de energia de um sistema HVAC e com o intuito de obter temperaturas desejadas para duas diferentes zonas, foi obtido com o auxilio de dois controladores (um controlador PID e um controlador inteligente em tempo real baseados na lógica fuzzy através da decomposição de pacotes wavelet, entropia e redes neurais) o controle da velocidade do motor do ventilador usando a temperatura requerida do evaporador enquanto que o intervalo de tempo para amortecimento das zonas, que é proporcional a vazão de ar, foi controlada pelas temperaturas exigidas na zona 1 e zona 2 . O mesmo ocorre no estudo de 
Karunakaran et al. (2010) [9], onde o ar condicionado operando sob as diferentes estratégias de ventilação e controlado pelo controlador de lógica fuzzy inteligente (FLC) pode ser considerado como uma tecnologia eficiente para alcançar um bom conforto térmico, qualidade do ar interior e conservação de energia.

Vale salientar também, conforme Peng e Du (2015) [10] destacaram em seu estudo, em que ambos os modos de funcionamento, tanto o compressor, quanto os ventiladores, eles devem trabalhar na frequência máxima para alcançar as capacidades máximas de aquecimento e resfriamento. Em contrapartida, para o consumo de energia mais baixo, a frequência do compressor e as frequências dos ventiladores do evaporador devem ser mínimas, enquanto as frequências dos ventiladores do condensador devem ser diferentes de acordo com o modo de operação. Por exemplo, no modo de aquecimento, a melhor frequência do ventilador do condensador muda de acordo com a condição de trabalho, onde aumenta com a temperatura exterior crescente. Contudo, no arrefecimento as frequências melhores do ventilador do condensador deve ser basicamente o mesmo em $35 \mathrm{~Hz}$ apesar das diferentes condições de trabalho.

No quesito operação de ventiladores, Mobley (2001) [11] destaca que quando aplicadas as leis dos ventiladores, a velocidade variável é um meio eficaz de controlar o desempenho de um ventilador, pois quando alterado a velocidade de rotação do ventilador pode controlar diretamente $o$ volume e a pressão do fluidodeslocado.

Em sistemas de refrigeração o evaporador é o equipamento indispensável para produção do frio. $\mathrm{O}$ evaporador é o agente direto de resfriamento, constituindo uma interface entre o processo e o circuito frigorífico, pois ele será o equipamento que propiciará aevaporação do fluido refrigerante através da transferência de calor do ambiente a ser refrigerado [2]. Esse fenômeno chamado transferência de calor acontece em todos os trocadores de calor e ocorre entre o fluido refrigerante e o ar, água ou outro fluido, sendo dependente da magnitude da diferença de temperatura entre os fluidos [12].

As características construtivas dos evaporadores variam principalmente de acordo com a carga térmica (quantidade de calor a ser retirado pelo sistema) e temperatura do ambiente necessária para conservação do produto. Em sistemas de pequeno porte, onde a carga térmica é mais reduzida, o evaporador é constituído de uma serpentina com menor geometria com um aglomerado de tubos por onde passa o fluido refrigerante (geralmente os fluidos halogenados) e um aletamento para aumentar a área de transferência de calor por meio da convecção natural de ar. Em alguns casos essas serpentinas evaporadoras são constituídas de uma ventoinha para auxiliar na movimentação de ar através da convecção forçada de ar, a fim de promover uma melhor transferência de calor [13].

Em sistemas de médio a grande porte, devido a maior demanda de carga térmica e a mais baixas temperaturas de operação, surgiram alternativas quanto ao uso do fluido refrigerante. A Amônia $\left(\mathrm{NH}_{3}\right)$, por exemplo, possui alta capacidade de transferência de calor, mas para isso, o evaporador deverá ser sempre de aço carbono ou aço inox e ser operado inundado, ao contrário dos sistemas que operam com fluidos halogenados, os quais normalmente são utilizados com tubulações de cobre e válvulas de expansão termostáticas [14]. Como os motores elétricos dos ventiladores dos evaporadores são comumente operados na frequência de acionamento de $60 \mathrm{~Hz}$, haverá sempre um consumo energético para manter a operação desses ventiladores, o que acaba contribuindo, também para o aumento da carga térmica do ambiente em função das irreversibilidades dos motores elétricos. Em razão disso, surge a motivação de estudar o comportamento de um conjunto motor e ventilador de um evaporador, em função da variação de velocidade do motor do ventilador através de um inversor de frequência.

Neste trabalho é realizada a avaliação de desempenho do conjunto motor de acionamento e ventilador de um evaporador de $\mathrm{NH} 3$ em diferentes frequências de acionamento por intermédio de um inversor de frequência no modo de operação 1, evaporador com as frestas vedadas e no modo de operação 2, evaporador sem vedação das frestas.

São avaliadas a velocidade e a vazão de ar, a potência consumida e a perda de carga do conjunto motor ventilador do evaporador quando alterada a frequência de acionamento. Também é feita a comparação do consumo de energia do conjunto motor e ventilador entre os modos de operação (evaporador vedado e evaporador sem vedação). 


\section{APARATO EXPERIMENTAL}

A estrutura de sustentação montada foi do tipo apoio com uso de perfis de aço conforme pode ser visualizado na Figura 1. Esta estrutura permitiu realizar a coleta de dados, como também garantir a estabilidade do evaporador quando em operação e prover um espaço mínimo da altura do chão para a inserção da bandeja de degelo.

O evaporador utilizado para avaliação de desempenho tem massa de $196 \mathrm{~kg}$ e possui toda carcaça, feixe tubular e aletamento construídos com aço galvanizado, constituindo-se de um único ventilador com motor com tecnologia alemã. As dimensões físicas do evaporador são de $0,655 \mathrm{~m}$ de largura, 1,080 $\mathrm{m}$ de comprimento e $0,585 \mathrm{~m}$ de altura e possuem integrados a ele, uma bandeja de degelo e um separador de líquido.

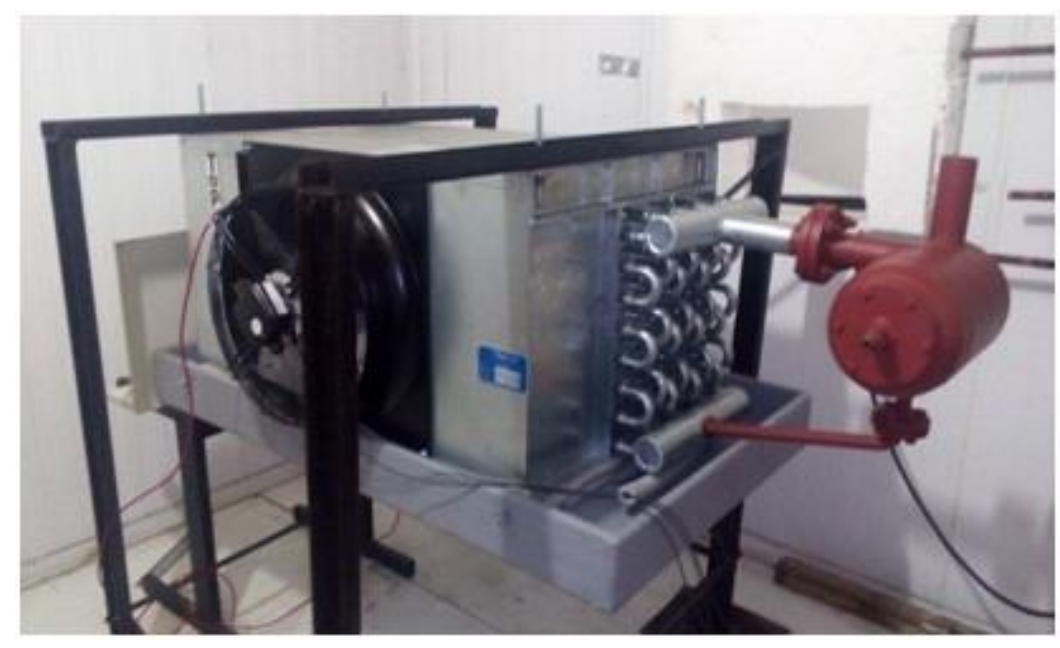

Figura 1: Evaporador

Inicialmente foi avaliado o desempenho do conjunto motor e ventilador a partir de 10 seções de medições, somente com o evaporador dispondo das frestas (espaço entre o evaporador e a bandeja de degelo) vedadas com o auxílio de poliestireno e poliuretano conforme visualizado na Figura 2. Entretanto, a fim de verificar se haveria aumento da velocidade e/ou menor consumo de energia do motor elétrico do ventilador quando operado com o evaporador em outra condição, foi estabelecido o modo de operação 2.

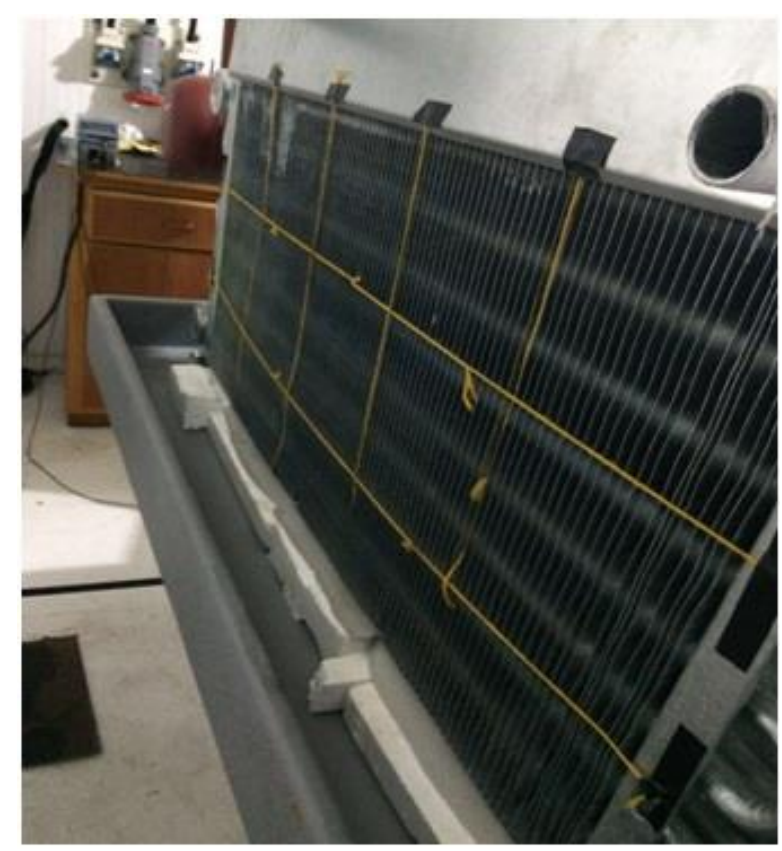

Figura 2: Modo de Operação 1- Evaporador operando com vedação nas frestas 
A realização dos ensaios e medições de velocidade do ar, potência e perda de carga para avaliação de desempenho do evaporador foram efetuadas dentro de uma câmara calorimétrica no laboratório de ensaios calorimétricos do campus Rio Grande do Instituto Federal de Educação, Ciência e Tecnologia e a metodologia dos ensaios foi baseada na NBR-15372 [15], onde consta que pelo menos um conjunto de condições especificadas devem ser mantidas para realização de um ensaio de desempenho aceitável. Para isso, a norma requer que o ambiente em que se realiza o ensaio deve ter propriedades do ar constantes como temperatura do ar em $20^{\circ} \mathrm{C}$, pressão local de $101 \mathrm{kPa}$, massa específica do ar de $1,2 \mathrm{~kg} / \mathrm{m}^{3}$ e por fim, evitar acúmulo apreciável de umidade nas superfícies da serpentina. Para tanto, foi utilizada uma câmara calorimétrica que permite a operação sob condições controladas. O acúmulo de gelo sobre a superfície do evaporador não ocorreu, uma vez que o mesmo foi ensaiado sem a circulação de fluido frigorígeno.

A primeira característica que foi determinada na avaliação de desempenho foi a velocidade de ar que percorre na área da face do evaporador ou como a NBR-15371 descreve, "Área de transferência de calor do lado ar do evaporador, sendo correspondida pela área externa dos tubos, chamada área primária, mais a área de superfície da aleta, chamada de área secundária" [16]. Desse modo, como consta a NBR 10142 [17], qualquer avaliação de vazão de ar em evaporadores, em virtude da grande extensão da área de troca térmica, a área da face do evaporador deve ser sempre dividida em quadrantes com o intuído de garantir melhor precisão em seus resultados, devendo ter demarcações com dimensões máximas de $0,2 \mathrm{~m}$ x 0,2 $\mathrm{m}$.

Então para a geometria do problema proposto, conforme ilustrada na Figura 3, ficou estabelecido 15 quadrantes na face do evaporador com dimensões de 0,200 x $0,160 \mathrm{~m}$ para uma área total de passagem de ar de $0,480 \mathrm{~m}^{2}$ (1,0 $\mathrm{m}$ na largura e $0,480 \mathrm{~m}$ na altura).

Os ensaios para medições da velocidade do ar na face do evaporador, potência consumida e perda de carga foram realizados com frequências de acionamento do motor elétrico do ventilador de 20 a $60 \mathrm{~Hz}$ com incrementos de $5 \mathrm{~Hz}$. O ajuste da frequência de acionamento do motor elétrico do ventilador do evaporador se deu por meio do inversor de frequência da WEG, o qual disponibiliza o monitoramento das grandezas elétricas como corrente elétrica e tensão da rede.

A obtenção dos resultados sucedeu-se devido a 90 seções de medição num intervalo de tempo de 18 horas para todas as 9 frequências estabelecidas. As 90 medições foram definidas de modo a permitir que fossem realizadas 10 seções de medição para cada frequência estabelecida. Para completar uma seção de medição, foi necessário um intervalo de tempo de 12 minutos para medir uma vez o consumo de energia, a perda de carga e realizar as leituras de velocidades nos 15 quadrantes da face do evaporador. Todos os dados foram equacionados e os gráficos construídos no programa Engineering Equation Solver (EES).

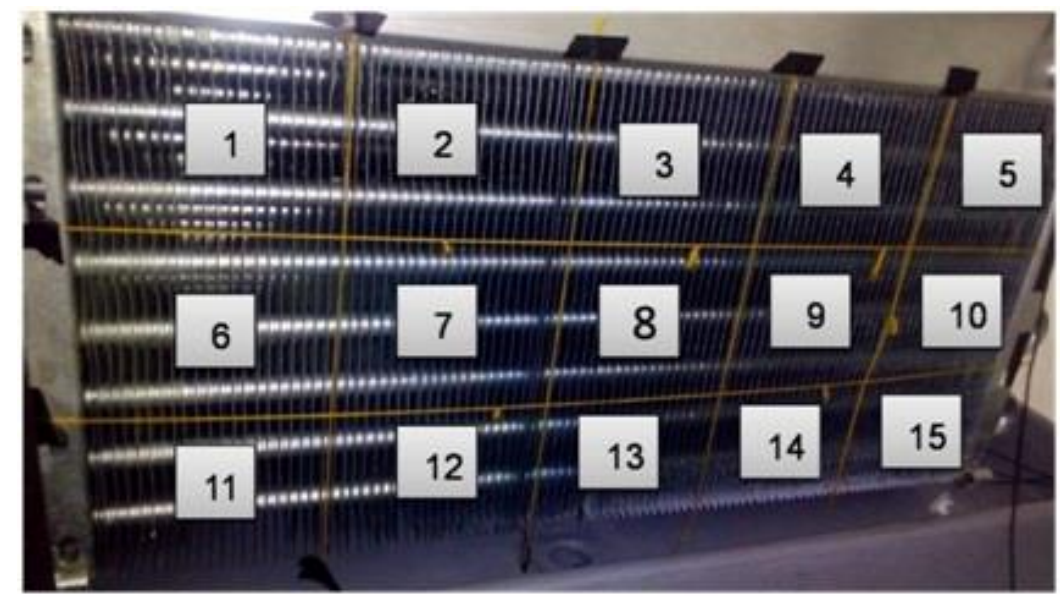

Figura 3: Demarcações utilizadas na face do evaporador para obtenção da velocidade do ar

Para determinação da vazão de ar foi utilizada a Eq. (1) da conservação de massa ou equação da continuidade, onde a vazão volumétrica de ar $(\dot{Q})$ em $\mathrm{m}^{3} / \mathrm{s}$ é definida pela multiplicação da velocidade média $(u) \mathrm{em} \mathrm{m} / \mathrm{s}$ pela área $(A)$ de face do evaporador $\mathrm{em}^{2}$ [18]. 


$$
\dot{Q}=\int_{A} u d a=u A
$$

Conforme Mobley (2001) [11] e Macintyre (1990) [19] as relações matemáticas que demonstram como os ventiladores operam em um sistema fixo ou a ventiladores geometricamente similares são chamadas leis dos ventiladores ou leis de semelhança. As leis dos ventiladores são usadas para calcular mudanças na vazão $(\dot{Q})$, pressão $(P)$ e potência $(\dot{W})$ quando o diâmetro $(D)$ do ventilador, a rotação $(N)$ ou massa específica $(r)$ do ar for alterado. Entretanto, para o trabalho proposto foi comparada a lei do ventilador, Eq.(2), somente com os resultados de potência consumida do motor elétrico, e para vazão de ar em função da variação da rotação, a qual apresenta uma relação direta.

$$
\dot{W}_{2}=\dot{W}_{1}\left(\frac{N_{2}}{N_{1}}\right)^{3}\left(\frac{D_{2}}{D_{1}}\right)^{5}\left(\frac{\rho_{2}}{\rho_{1}}\right)
$$

Para a determinação das grandezas elétricas do motor do ventilador foi utilizado um medidor do modelo UPD 200, instrumento esse que realiza a leitura dos valores de potência consumida, fator de potência e consumo de energia do motor elétrico do ventilador. Porém, devido a grande instabilidade e oscilações nas leituras de potência e fator de potência, o cálculo da potência consumida $(\dot{W})$ do motor elétrico deu-se através da Eq.(3), com a divisão do consumo de energia $\left(C E_{m}\right)$ em kWh medido através do UPD200 por certo período tempo, sendo nesse caso o intervalo de tempo $(t)$ definido em 0,2 horas (ou 12 minutos). Este período de tempo foi definido em função de ter se apresentado como o intervalo suficiente para realização de uma seção de medição de velocidades nos15 quadrantes do evaporador.

$$
\dot{W}=\frac{C E_{m}}{t}
$$

Para um sistema HVAC (Heating, ventilation and air conditioning), os dutos e tubos de transporte de fluidos, os feixes tubulares das serpentinas (evaporadores e condensadores), válvulas e acessórios, qualquer que seja sempre vão oferecer certa resistência ao escoamento do fluido. Essa resistência é normalmente chamada de perda de carga na mecânica dos fluidos. Fisicamente significa a perda de energia mecânica pela unidade de massa de um fluido causada pelo atrito das paredes internas e da turbulência do escoamento entre dois pontos de um trecho. A perda de carga nada mais é do que uma variação de pressão entre dois pontos de um trecho [18].

O diferencial de pressão do ar provocada pelo feixe tubular e pelo aletamento do evaporador foi obtido a partir de um manômetro em $U$ (Figura 4), tendo como fluido manométrico a água. E como o manômetro funciona em função da diferença de pressão, para este caso conectou-se a primeira tomada de pressão $\left(h_{2}\right)$ na sucção do ventilador por meio de um orifício disposto no evaporador. Já a segunda tomada de pressão $\left(h_{1}\right)$ fixou-se sob ao ar atmosférico (face do evaporador).

A fim de garantir uma melhor visualização da deflexão da água provocada pelo diferencial de pressão, as medições foram realizadas com o manômetro sob uma inclinação de $4,75^{\circ}$ em relação ao plano horizontal. Com o uso da Eq.(4), foi determinada a perda de carga, $H$, do ar ao atravessar a serpentina.

$$
H=\operatorname{sen} 4,75^{\circ}\left(h_{2}-h_{1}\right)
$$




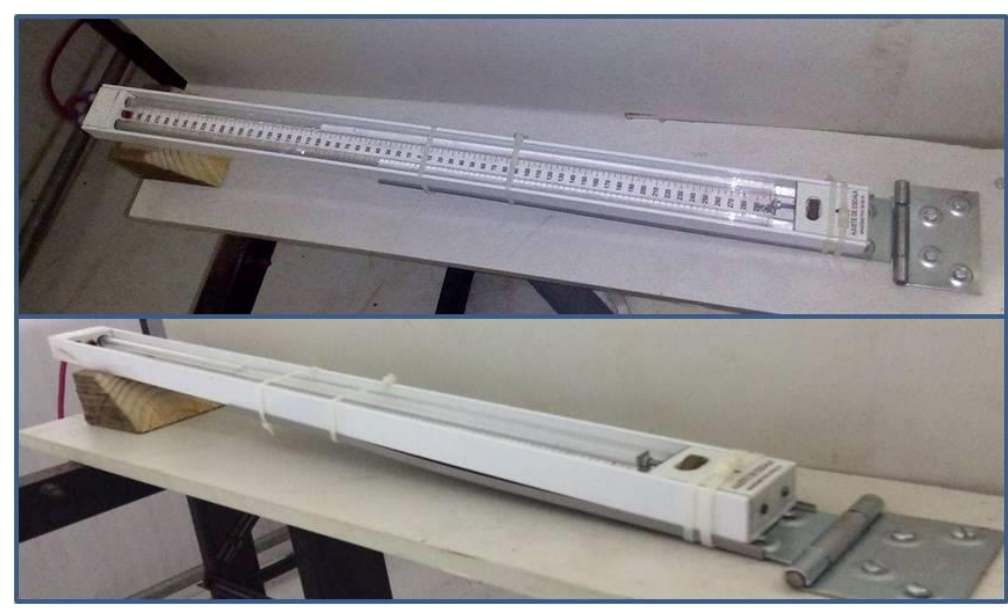

Figura 4: Manômetro em U inclinado

Para descarte de dados inconsistentes foi utilizado o critério de Chauvenet [20], onde consiste em: Caso a relação desvio $\left(d_{i}\right)$ de qualquer grandeza sobre desvio padrão $(\sigma)$ da amostra for maior que a relação $d_{i} / \sigma$ que é tabelado em função do numero de medições, tal grandeza deverá ser excluída e por fim efetuada uma nova média aritmética da amostra.

As incertezas de medição dos instrumentos utilizados constam na Tabela 1.

Tabela 1: Incerteza dos instrumentos

\begin{tabular}{ccc}
\hline Instrumento & Grandeza & Incerteza \\
\hline \multirow{2}{*}{ Anemômetro } & Temperatura & $0,1^{\circ} \mathrm{C}$ \\
& Velocidade & $0,1 \mathrm{~m} / \mathrm{s}$ \\
\hline \multirow{2}{*}{ Inversor de Frequência } & Frequência & $0,1 \mathrm{~Hz}$ \\
& Corrente & $0,1 \mathrm{~A}$ \\
& Tensão & $1 \mathrm{~V}$ \\
\hline Manômetro em U & Pressão & $1 \mathrm{mmca}$ \\
UPD 200 & Consumo de energia & $0,001 \mathrm{kWh}$ \\
\hline
\end{tabular}

\section{RESULTADOS E DISCUSSÃO}

\subsection{PERFIL DE VELOCIDADE E VAZÃO}

Com a velocidade média de ar determinada em cada ponto de medição para todas as frequências de acionamento, para o evaporador com a vedação e para o evaporador sem vedação (respectivamente Figuras 5 e 6), foi verificado um aumento da velocidade média nos pontos de medição do evaporador quando a frequência de acionamento do motor do ventilador é aumentada. Quando a frequência de acionamento é alterada de $20 \mathrm{~Hz}$ até $60 \mathrm{~Hz}$, a velocidade média do ar que passa no ponto de medição 1 aumenta de $1,62 \mathrm{~m} / \mathrm{s}$ a 4,22 m/s, depois no ponto de medição 2 , a velocidade aumenta de $1,62 \mathrm{~m} / \mathrm{s}$ para $4,39 \mathrm{~m} / \mathrm{s}$, e assim ocorre nos outros pontos de medição para o evaporador com as vedações. Porém para o evaporador sem vedação, quando a frequência de acionamento é alterada de $20 \mathrm{~Hz}$ para $60 \mathrm{~Hz}$, a velocidade média do ar que passa no ponto de medição 1 aumenta de $1,4 \mathrm{~m} / \mathrm{s}$ para $3,5 \mathrm{~m} / \mathrm{s}$ e depois no ponto de medição 2 a velocidade aumenta $1,43 \mathrm{~m} / \mathrm{s}$ para $3,63 \mathrm{~m} / \mathrm{s}$. Isto ocorre, pois ao retirar a vedação, parte do escoamento tende a ser através das frestas, reduzindo a vazão de ar que atravessa o feixe tubular. 


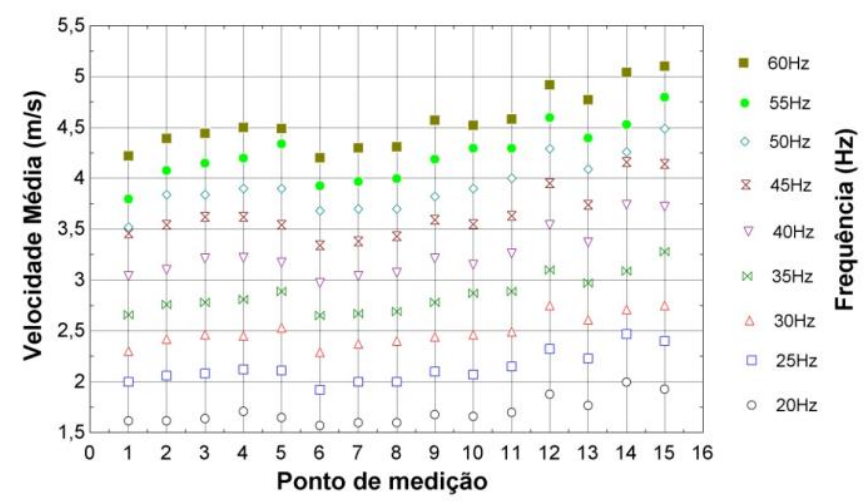

Figura 5: Variação da velocidade média do ar de acordo com o ponto de medição e também pela frequência de acionamento - Evaporador vedado

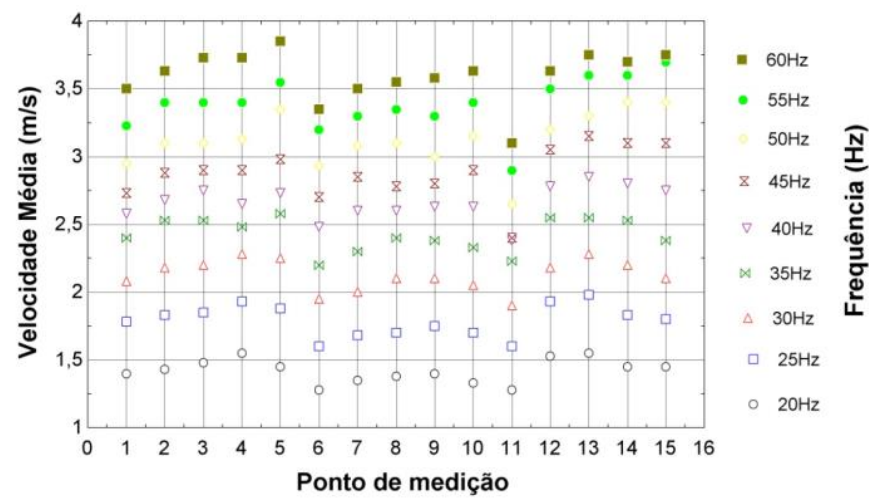

Figura 6: Variação da velocidade média do ar de acordo com o ponto de medição e também pela frequência de acionamento - Evaporador sem vedação

Com relação à distribuição de velocidade de ar na face do evaporador, foi verificado que para todas as frequências de acionamento do motor elétrico nas duas situações de operação, a velocidade não é homogênea em toda face do evaporador, tendo picos maiores de velocidades e picos menores de velocidade em determinados pontos de medição.

Para o evaporador que opera vedado foi observado que as topologias da distribuição de velocidades na face do evaporador diferem pouco com a variação da frequência. Um exemplo destas topologias para as frequências de 20 e $60 \mathrm{~Hz}$, pode ser visualizada nas Figuras 7 e 8 , respectivamente. As maiores velocidades, expressas pela cor vermelha, são localizadas na parte inferior direita da face do evaporador próximo ao ponto de medição 15 com velocidade de 1,93 $\mathrm{m} / \mathrm{s}$ para $20 \mathrm{~Hz}$ e $5,1 \mathrm{~m} / \mathrm{s}$ para $60 \mathrm{~Hz}$. Os menores valores de velocidade, expressos pela cor azul, se localizam na parte superior esquerda da face do evaporador próximo ao ponto de medição 1 com velocidade de $1,62 \mathrm{~m} / \mathrm{s}$ para $20 \mathrm{~Hz}$ e $4,22 \mathrm{~m} / \mathrm{s}$ para $60 \mathrm{~Hz}$, tendo algumas oscilações com menores velocidades também no centro da face do evaporador (pontos de medição 7 e 8 ).

Já para a situação em que o evaporador opera sem as vedações nas frestas, as velocidades medidas foram menores, não seguindo o mesmo padrão, como é o caso do evaporador vedado que alguns pontos de medições já têm definidas as maiores e menores velocidades, mesmo quando alterada a frequência de acionamento. Dessa maneira, foi observado que para as frequências de acionamento de $20 \mathrm{~Hz}$ e $60 \mathrm{~Hz}$ (Figuras 9 e 10, respectivamente), as maiores velocidades, expressas pela cor vermelha, são localizadas na parte direita tanto na região superior e inferior do evaporador e as menores velocidades, expressas nas cores azul e verde se localizam na parte esquerda das regiões inferior e superior da face do evaporador. Assim, o aumento da velocidade devido a este tipo de situação, sempre se verifica no sentido esquerda para direita, como é caso da Figura 10, onde há o aumento de velocidade de $3,5 \mathrm{~m} / \mathrm{s}$ (ponto de medição 1) até $3,85 \mathrm{~m} / \mathrm{s}$ (ponto de medição 5), e depois na face inferior do evaporador, há o aumento da velocidade de 3,1 $\mathrm{m} / \mathrm{s}$ (ponto de medição 11) para $3,75 \mathrm{~m} / \mathrm{s}$ (ponto de medição 15). Esta tendência que mostra 
menores velocidades do lado esquerdo da face do evaporador em todos os casos analisados, provavelmente seja devido aos vórtices provocados na sucção do ventilador, provocando um deslocamento desuniforme do ar na parte da frente do feixe tubular.

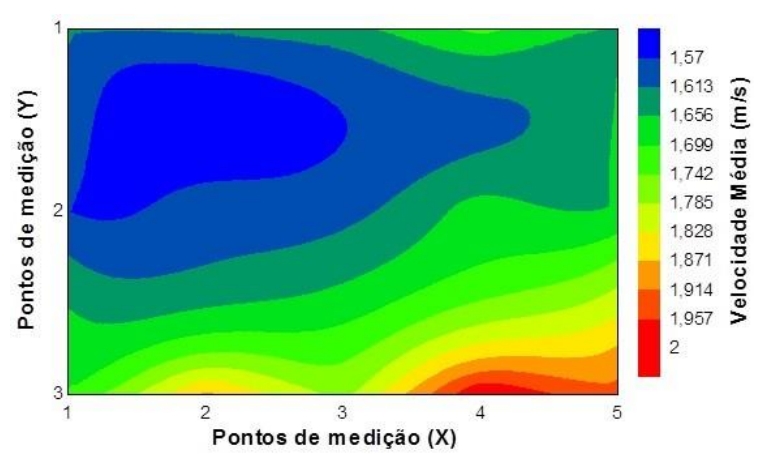

Figura 7: Distribuição de Velocidade na frequência de $20 \mathrm{~Hz}$-evaporador vedado

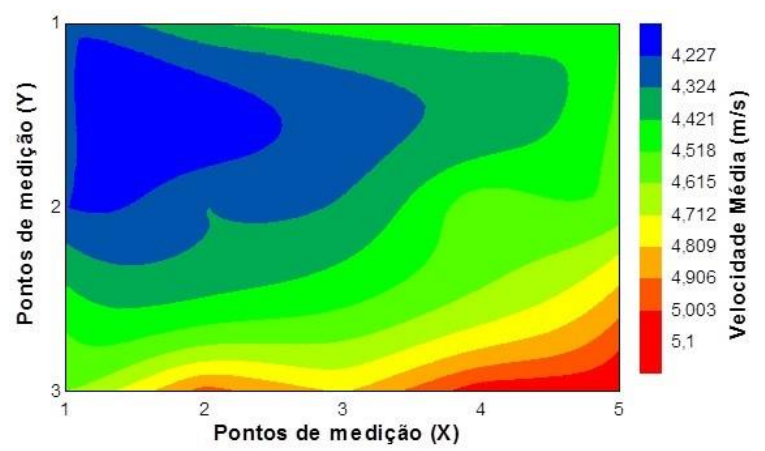

Figura 8: Distribuição de Velocidade na frequência de $60 \mathrm{~Hz}$-evaporador vedado

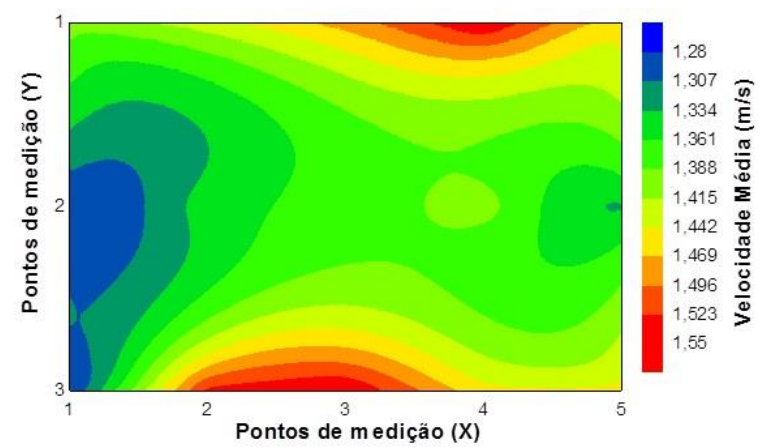

Figura 9: Distribuição de Velocidade na frequência de $20 \mathrm{~Hz}$ - evaporador sem vedação

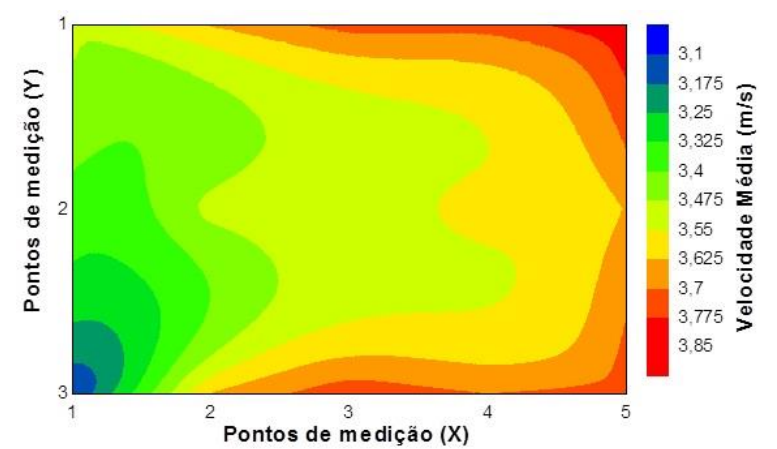

Figura 10: Distribuição de Velocidade na frequência de $60 \mathrm{~Hz}$-evaporador sem vedação 
Com a velocidade média do ar obtida nos 15 pontos de medição para cada frequência de acionamento estabelecida, foi definida a curva de velocidades médias para cada frequência para as situações em que o evaporador opera vedado e sem vedação (Figura 11).

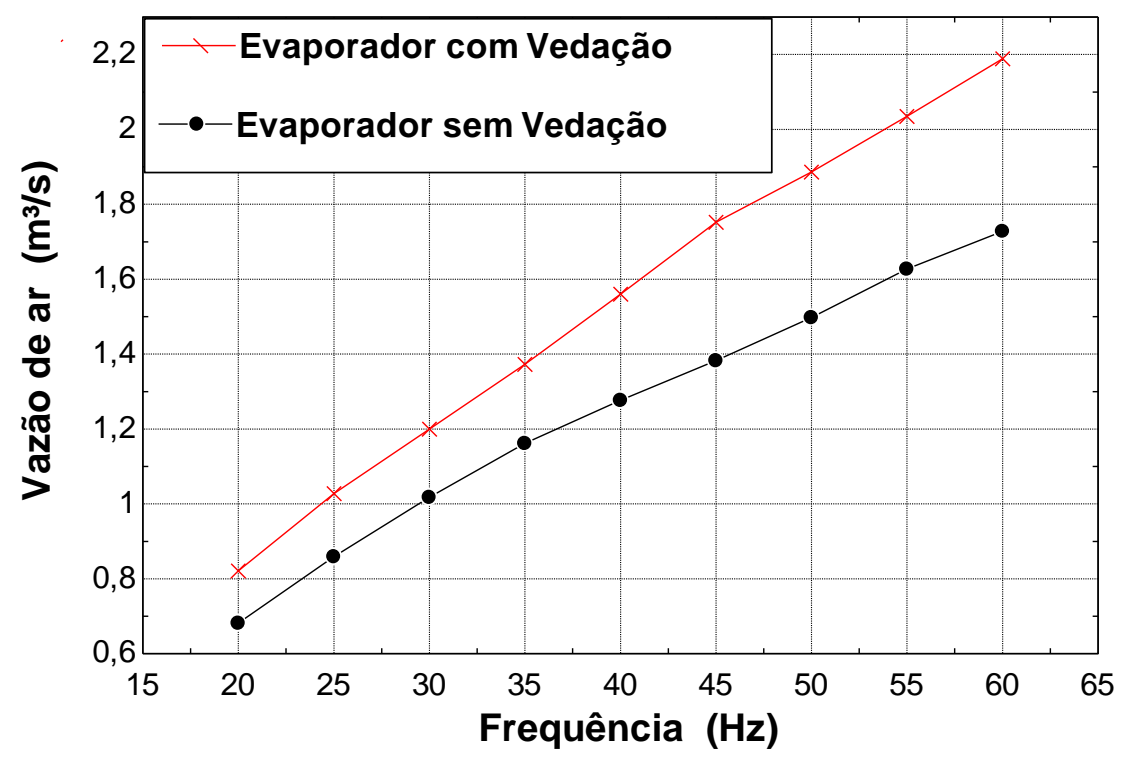

Figura 11:- Velocidade do ar de acordo com a frequência

Com relação à velocidade, o melhor desempenho do evaporador ocorre quando o mesmo opera com a vedação em suas frestas, apresentando um aumento de velocidade para as frequências estabelecidas próximas a $21,1 \%$ em relação ao evaporador sem os isolantes, conforme ilustrado na Figura 12.

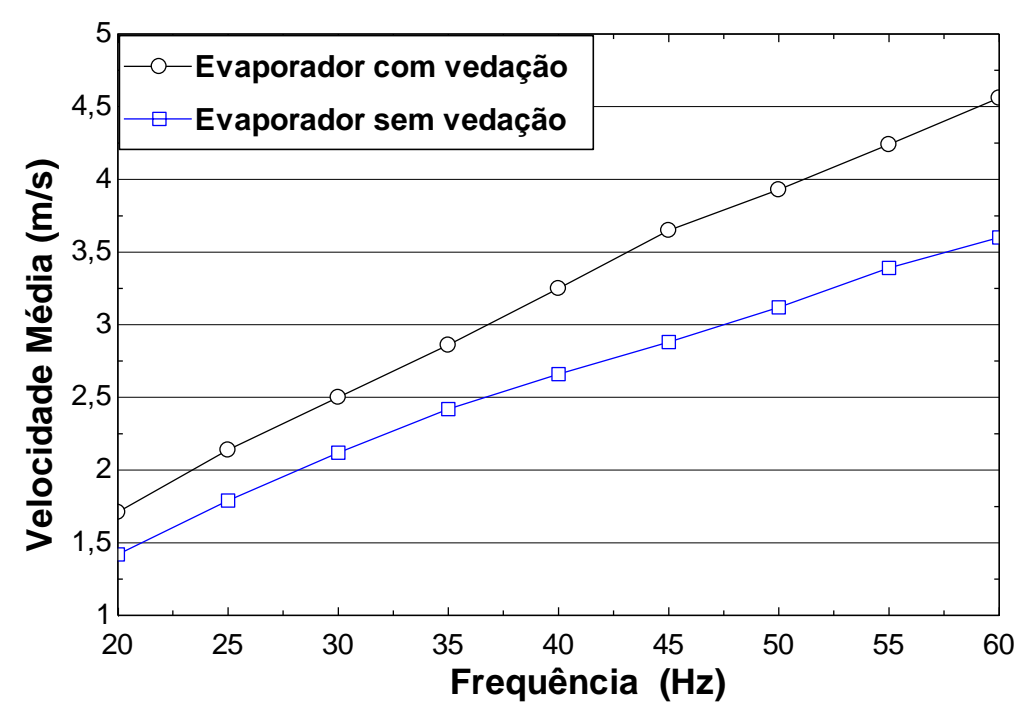

Figura 12: Variação da velocidade média do ar - evaporador vedado x evaporador sem vedação

\subsection{POTÊNCIA CONSUMIDA PELO MOTOR ELÉTRICO}

Com a média das potências consumidas obtida a partir dos valores das seções de medições para os respectivos modos de operação, evaporador vedado e evaporador sem vedação, foram constatados que em termos de consumo de energia (Figura 13), o evaporador com as vedações possui um consumo maior de energia em relação ao evaporador sem a vedação. Para o acionamento à 60 
$\mathrm{Hz}$, a potência foi $0,61 \%$ maior para o caso com vedação. Para todas as outras frequências a diferença de consumo também se mostrou pouco significativa.

Observa-se também através das Figuras 13 e 14 que sempre haverá o aumento da potência consumida do motor elétrico quando é aumentada a vazão de ar, que nesse caso é uma função do aumento da frequência de acionamento do motor elétrico. Dessa maneira, considerando-se o modo de operação 1 , em que o ventilador opera com o evaporador vedado, verifica-se que a potência consumida aumentará de $0,077 \mathrm{~kW}$ para $0,7435 \mathrm{~kW}$ quando a vazão de ar aumentar de $2955 \mathrm{~m}^{3} / \mathrm{h}$ para $7880 \mathrm{~m}^{3} / \mathrm{h}$, para frequência de acionamento correspondentes de $20 \mathrm{~Hz}$ e $60 \mathrm{~Hz}$, respectivamente. Esta tendência já era esperada, pois é concordante com as leis dos ventiladores.

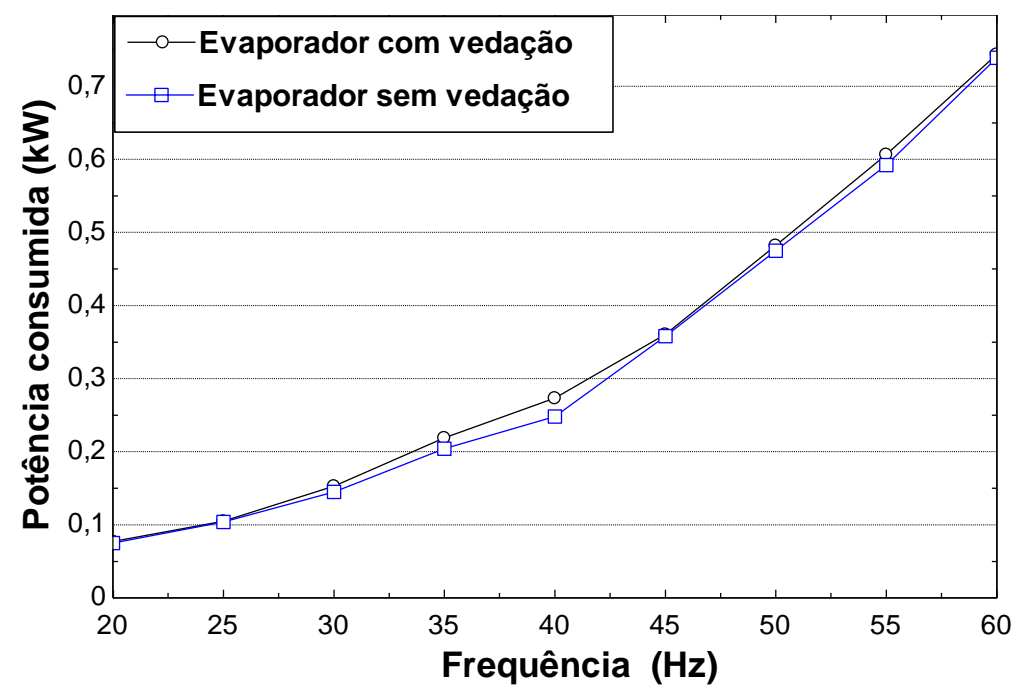

Figura 13: Variação da potência consumida - evaporador vedado x evaporador sem vedação

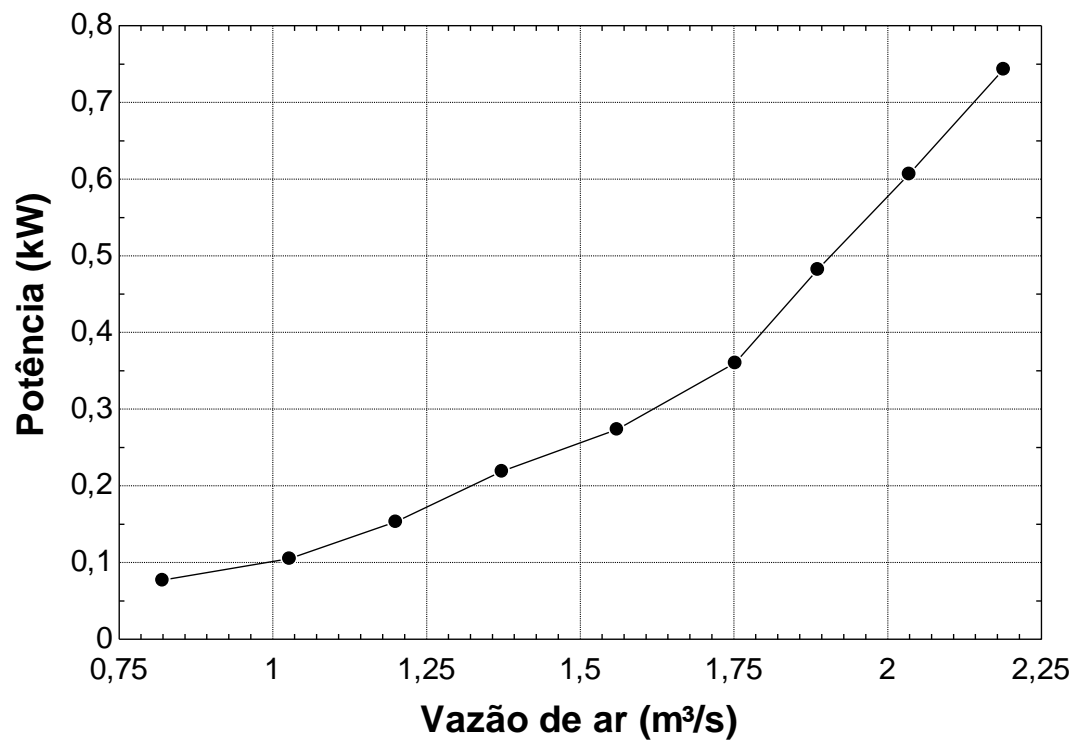

Figura 14: Variação da potência consumida em função da vazão de ar para o evaporador vedado

$\mathrm{Na}$ Figura 15 verifica-se que o consumo de energia $(\mathrm{kWh})$ para cada $1 \mathrm{~m}^{3} \mathrm{de}$ ar deslocado pelo ventilador é uma função da Relação $\dot{W} / \dot{Q}$ (Potência consumida em $\mathrm{kW}$ sobre a vazão de ar em $\mathrm{m}^{3} / \mathrm{h}$ ) e que varia de acordo com a frequência de acionamento. Os desvios não seguem um padrão, tendo um desvio médio do evaporador sem vedação de $18,47 \%$ em relação ao evaporador com vedação. Como é possível observar, o evaporador vedado apresenta maior consumo em relação ao evaporador sem vedação, pois com a vedação a vazão de ar através do feixe tubular é maior. 
Embora o evaporador vedado apresente potência maior consumida, este modo de operação, será mais eficiente em relação ao modo de operação 2 , em função dos seus altos valores de velocidades e baixos valores da relação $\dot{W} / \dot{Q}$. O consumo de energia para cada $\mathrm{m}^{3} \mathrm{de}$ ar deslocado pelo ventilador aumenta de $2,60 \times 10^{-5} \mathrm{kwh} / \mathrm{m}^{3}$ (quando acionado a frequência de $20 \mathrm{~Hz}$ ) para $9,40 \times 10^{-5} \mathrm{kwh} / \mathrm{m}^{3}$ (quando acionado a frequência de $60 \mathrm{~Hz}$ ) para o evaporador vedado. Visto que, no modo de operação 2 , em que o evaporador está sem vedação, os valores da relação $\dot{W} / \dot{Q}$ serão maiores, aumentando de $3,06 \times 10^{-5} \mathrm{kwh} / \mathrm{m}^{3}$ para $11,08 \times 10^{-5} \mathrm{kwh} / \mathrm{m}^{3}$, para a mesma faixa de acionamento estabelecida.

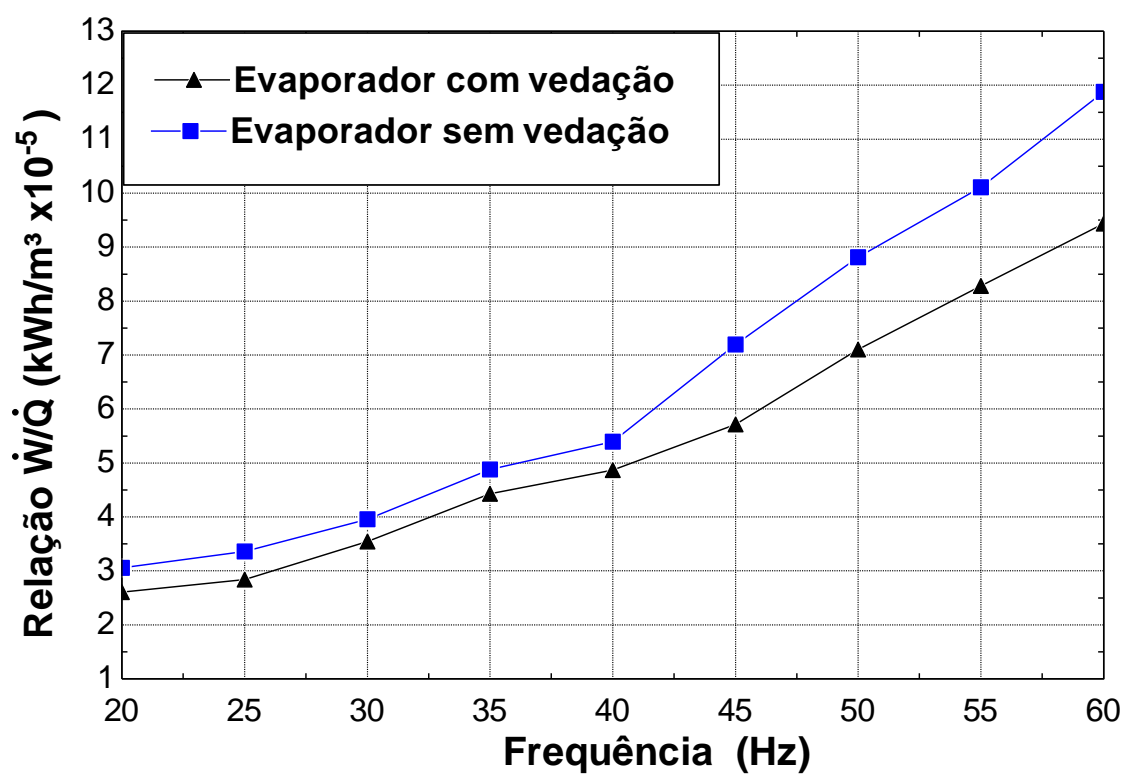

Figura 15: Variação da potência por unidade de volume consumida

Através da Figura 16 pode-se observar que a potência elétrica medida $\left(\dot{W}_{1}\right)$ apresentou desvios de $0 \%$ a $65 \%$ em relação à potência calculada pelas leis dos ventiladores $\left(\dot{W}_{3}\right)$. Essa discrepância ocorre devido às irreversibilidades em forma de ruído e energia térmica dissipada pelo inversor de frequência e pelo motor elétrico do ventilador, como também a perda inicial ao tirar o ventilador do repouso. Dessa maneira considerando essas perdas ou irreversibilidades do sistema, foi determinado um fator de correção equacionado nas leis dos ventiladores, o qual ficou apresentando pela curva de cor azul e praticamente sobreposto da curva de cor preta para potência medida com um desvio entre $0 \%$ a $11 \%$. 


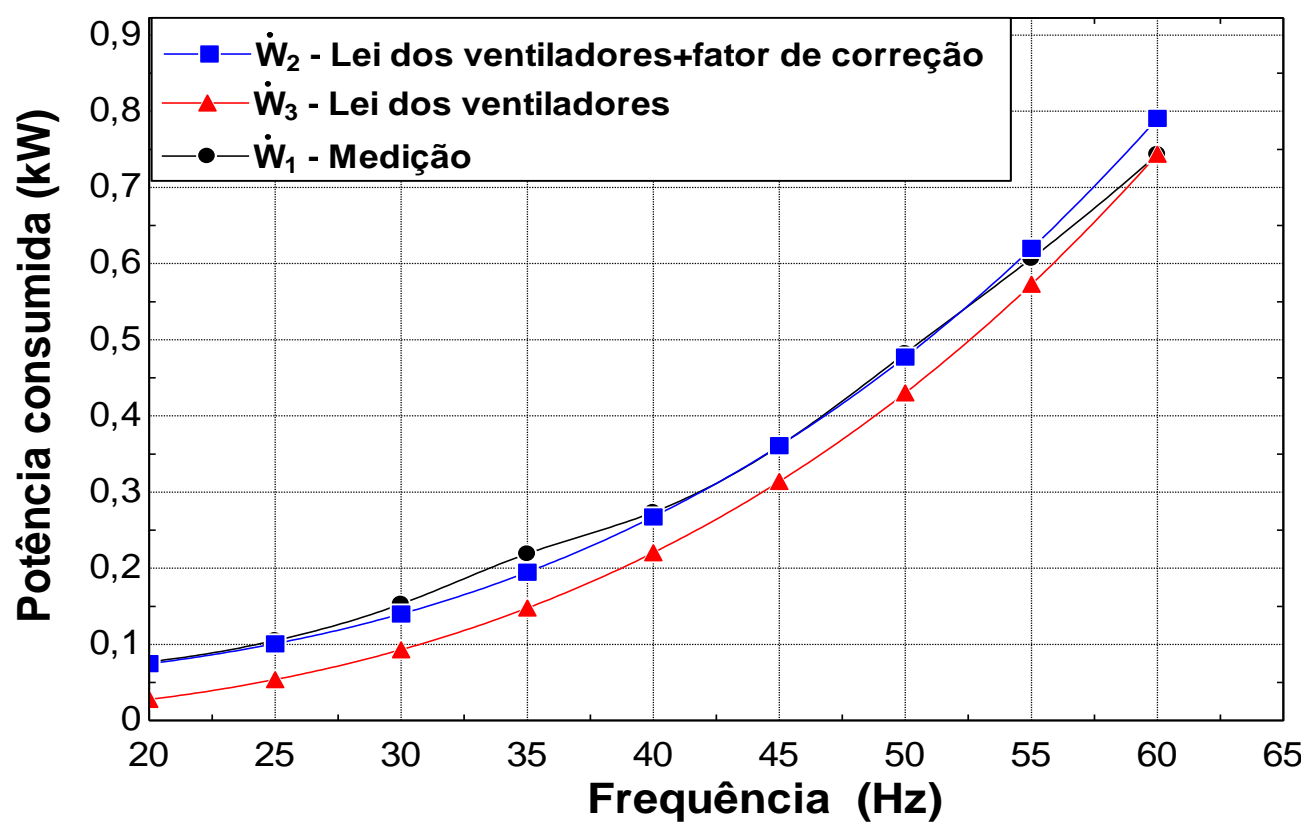

Figura 16: Potência consumida em função das leis dos ventiladores

\subsection{PERDA DE CARGA}

Para a perda de carga foram considerados somente os resultados do modo de operação 1 (evaporador vedado), tendo sido desprezados os resultados de perda de carga para o evaporador sem vedação, devido à diversas oscilações de valores apresentadas durante as medições.

Dessa maneira, conforme observado na Figura 17, verifica-se que os valores de perda de carga estão relacionados com a frequência de acionamento, ou seja, quanto mais alta a frequência de acionamento do ventilador, maior é a velocidade de ar imposta na área de troca térmica do evaporador, consequentemente são geradas maiores perda de carga no escoamento do ar ao longo do feixe tubular até o ventilador. Em razão disso para um aumento de frequência de acionamento de $20 \mathrm{~Hz}$ até $60 \mathrm{~Hz}$ e consequentemente aumento de vazão de ar, há o aumento de perda de carga de 1,75 mmca a 7,69 mmca.

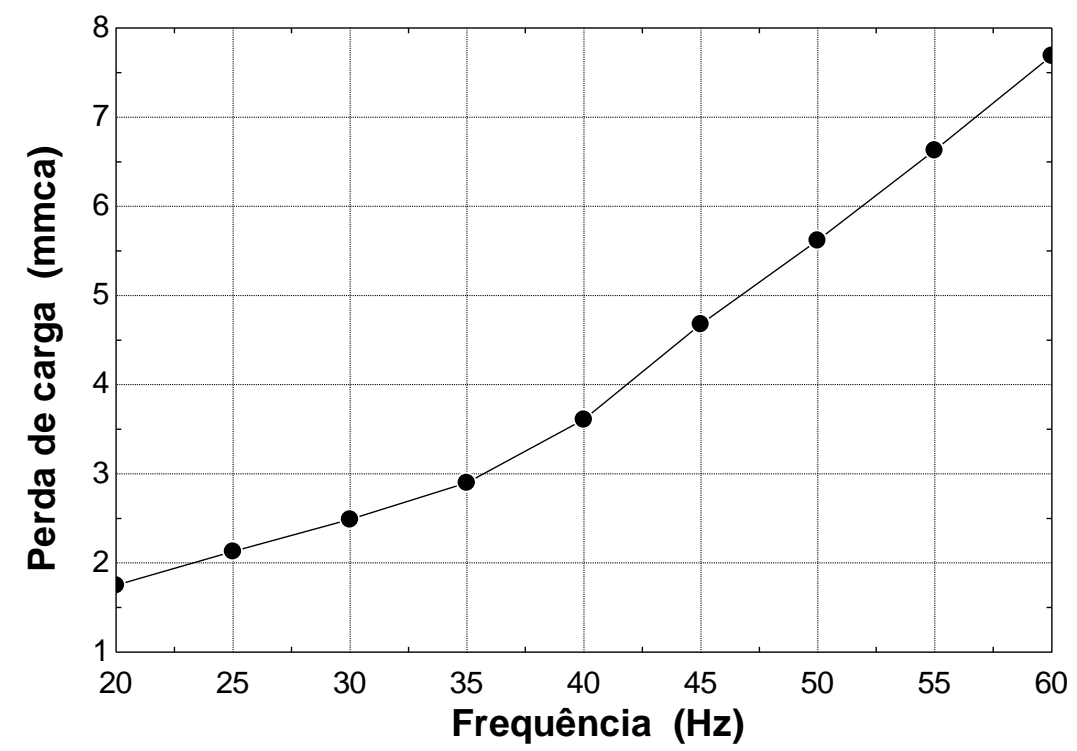

Figura 17: Perda de carga em função da frequência de acionamento para evaporador vedado 


\section{CONCLUSÃO}

Neste trabalho foi ensaiado um evaporador que opera com amônia como fluido refrigerante, frequentemente empregado em câmaras frigoríficas industriais. Para ambos os modos de operação do evaporador, o comportamento da vazão de ar será o mesmo, tendo vazões de ar altas sob frequências de acionamento altas e vazões de ar baixas para frequência de acionamento baixa. No entanto, quando considerada a operação do evaporador vedado, foi constatado que há um aumento de velocidade próximo aos $21,1 \%$ em relação ao evaporador que opera sem vedação em praticamente todas as frequências estabelecidas. $\mathrm{O}$ consumo de energia, para ambos os casos analisados (com vedação e sem vedação) foi muito semelhante, apresentando diferenças pouco significativas. Para todas as frequências de operação ensaiadas, as maiores velocidades ocorreram nos pontos de medições inferiores do lado direito (pontos 14 e 15) da área de face, e quando aplicadas a leis dos ventiladores, obtiveram-se valores de potências próximas as medidas.

Com as frestas vedadas, verificou-se que a potência consumida aumentará de $0,077 \mathrm{~kW}$ para $0,7435 \mathrm{~kW}$ quando a vazão de ar aumentar de $2955 \mathrm{~m}^{3} / \mathrm{h}$ para $7880 \mathrm{~m}^{3} / \mathrm{h}$, para frequências de acionamento correspondentes de $20 \mathrm{~Hz}$ e $60 \mathrm{~Hz}$, respectivamente.

A carga térmica a ser transferida pelo evaporador sofrerá uma redução proporcional à vazão de ar imposta ao mesmo. Desta forma, em situações em que o processo de resfriamento (ou congelamento) esteja em fase final ou em casos de produção parcial, o consumo provocado pelos evaporadores poderá ser substancialmente reduzido. Considerando a situação em que apenas metade da capacidade frigorífica seja demandada, o consumo de energia elétrica dos evaporadores poderá ser reduzido para aproximadamente $20 \%$ do consumo a plena carga. Além disso, deve-se esperar uma redução também, na pressão de sucção dos compressores, o que poderá permitir uma redução na capacidade destes, propiciando economia também nestes equipamentos, os quais são os maiores consumidores de energia em uma sala de máquinas.

Através dos ensaios, também se verificou valores de perda de carga de 1,75 mmca à 7,69 mmca com o aumento da vazão de ar nas faixas experimentadas.

\section{AGRADECIMENTOS}

O primeiro e segundo autores agradecem ao fomento interno do Instituto Federal de Educação, Ciência e Tecnologia do Rio Grande do Sul (IFRS) pelo apoio financeiro. Todos os autores agradecem à empresa Top Cold Refrigeração Industrial Ltda por disponibilizar o equipamento para a execução dos testes e à empresa Less Energy Engineering pelo apoio técnico.

\section{REFERÊNCIAS BIBLIOGRÁFICAS}

1. Qureshi T, Tassou S. Variable-speed capacity control in refrigeration systems, Applied Thermal Engineering. 1996 Feb;16(2):103-113, doi.org/10.1016/1359-4311(95)00051-E

2. Stoecker W, Jabardo JS. Refrigeração Industrial, $2^{a}$ Ed., São Paulo: Edgard Blucher; 2002. 371p.

3. Pinnola C, Vargas J, Buiar C, Ordonez J. Energy consumption reduction in existing hvac-r systems via a power law controlling kit. Applied Thermal Engineering. 2015 May;82:341-350, doi.org/10.1016/j.applthermaleng.2015.02.065

4. Plessis G, Liendenberg L, Mathews E. The use of variable speed drives for cost- effective energy savings in south african mine cooling systems. Applied Energy. 2013 May;111:16-27, doi.org/10.1016/j.apenergy.2013.04.061

5. Zhifang X, Lin S. Modeling and experimental investigation of a variable speed drive water source heat pump. Tsingua Sience and Technology. 2010 August;15(4):434-440, doi.org/10.1016/S10070214(10)70084-5

6. Yu F, Chan K. Modelling of the coefficient of performance of an air-cooled screw chiller with variable speed condenser fans. Building and Environment. 2006 Aug;41:407-417, doi.org/10.1016/j.egypro.2017.03.070

7. Al-Bassam E, Alasseri R. Measurable energy savings of installing variable frequency drives for cooling towers fans, compared to dual speed motors. Energy and Buildings. 2013 Dec;67:261-266, doi.org/10.1016/j.enbuild.2013.07.081 
8. Soyguder S. Intelligent system based on wavelet decomposition and neural network for predicting of fan speed for energy saving in hvac system. Energy and Buildings. 2011 Apr;43(4):814-822, doi.org/10.1016/j.enbuild.2010.12.001

9. Karunakaran R, Iniyan S, Goic R. Energy efficient fuzzy based combined variable refrigerant volume and variable air volume air conditioning system for buildings. Applied Energy. 2010 Apr;87(4): 11581175, doi.org/10.1016/j.apenergy.2009.08.013

10. Peng Q, Du Q. Performance evaluation of a variable frequency heat pump air conditioning system for electric bus. International Journal of Fluid Machinery and Systems. 2015 Mar;8(1):13-22, doi.org/10.5293/IJFMS.2015.8.1.013

11. Mobley RK. Plant Engineer's Handbook. 1a Ed, Butterworth- Heinemann; 2001. 2400 p.

12. Çengel Y, Ghajar A. Transferência de calor e massa: uma abordagem prática, $4^{\mathrm{a}}$ Ed, Porto Alegre: AMGH; 2012. 906p.

13. Castro J. Refrigeração comercial e climatização industrial, 2a Ed. São Paulo: Hemus; 2004. 240p.

14. Costa EC. Refrigeração, 3a Ed. São Paulo: Blucher; 1982. 324p.

15. ABNT. NBR 15372: Resfriadores de Ar para refrigeração - Método de Ensaio; 2006.

16. ABNT. NBR 15371: Evaporadores tipo circulação forçada para refrigeração - Especificação, requisitos de desempenho e identificação; 2006.

17. ABNT. NBR 10142: Condicionador de Ar Tipo Compacto - Ensaios de aceitação em Fábrica Método de Ensaio; 1987.

18. Fox R, McDonald A, Pritchard, P. Introdução à Mecânica dos Fluidos, 8a Ed. Rio de Janeiro: LTC; 2014. 871p.

19. Macintyre A. Ventilação Industrial e controle da Poluição, 2a Ed. Rio de Janeiro: LTC; 1990. 416p.

20. Holman J. Experimental Methods for Engineers, 6 Ed. New York: McGraw-Hill; 1994. 640p.

21. Enginerring Equation Solver. Manual. F-chart Software, 〈http://www.fchart.com>. Acesso em 10 de outrubro de 2016 